\title{
UnleAshing KNOWLEDGE CREATION AND SHARING IN A REFLECTIVE OPEN EDUCATION
}

\author{
Riadh Habash \\ School of Electrical Engineering and Computer Science, University of Ottawa, Ottawa, Canada \\ rhabash@site.uottawa.ca
}

\begin{abstract}
The volume of knowledge that engineers are collectively called upon to know is increasing far more rapidly than the capability of engineering curricula to cover it. This reality necessitates rethinking a learner-centered pedagogy by moving from acquisition and possession of knowledge to creation of knowledge, which comes about through reflection, sharing, and interaction in an active learning environment. This paper explores such pedagogy of blended learning that may contribute to the development and mastery of competencies and advance the quality of engineering education. This pedagogy is based on the knowledge creation framework of "acquire-reflect-share-apply" to boost students' creativity and innovation in two engineering disciplines (Electrical and Mechanical) at the University of Ottawa. Peer evaluation and questionnaire were administered to measure the effectiveness of reflection practice to students' learning. Presented also are two open educational resources (g9toengineering.com; greenengineers.ca) developed by the author as an online model to enable knowledge sharing and transfer.
\end{abstract}

Keywords: Reflection practice, knowledge creation, case-based learning, project-based learning, learning by doing, digital media, open education.

\section{INTRODUCTION}

In today's knowledge society, memorization of facts and procedures will not be enough, where students are active learners who view themselves as participants in creating knowledge and new ideas [1]. In addition to learning content knowledge, there is a need to develop multiple skills like problem-solving, critical thinking, collaboration and communication.

Students learn in many ways; by seeing and hearing, reflecting and acting, reasoning logically and intuitively, memorizing and visualizing, drawing analogies and building mathematical models [2]. All above approaches promote interest and open minds in classes, however learning through reflection as a process of engagement enables learners to explore, examine, and understand their feeling and thinking.

The modern pedagogy has evolved over time through contribution from Buddha, Dewey, Schon, Smyth, Osterman, Colton, Valli and others in order to advance student's creativity. Today, education is less about students acquiring knowledge. Instead, the classroom should focus on offering an experience that builds the capacity for living and working in a connected professional world by bringing together theory and practice, and such an experience may only be successful if it spurs curiosity, unleashes creativity, and demands teamwork [3].

Sfard [4] labelled the "acquisition" metaphor for learning as something which results in the personal acquisition of knowledge and skills. Attention may be paid to other conceptions of learning, such as "learning as participation" or "learning as knowledge creation". For example, if learning is seen as a matter of acquiring knowledge, then tools should be set in place for students to help them acquire that knowledge. But if learning is seen as a matter of participating in a practice, tools are there to be mastered, as instruments of that practice [5]. However, if learning is seen as a matter of collaboration in knowledge creation, new tools should be designed mainly by teachers who should evolve into creative workers and become learning resource coordinators.

Concerning engineering, education responded to the explosion in knowledge by continually developing and spawning new areas of focus in various disciplines. As more of these areas arise, the depth of individual knowledge increases, but the breadth can dramatically decrease. This poses a challenge to an engineering future where interdisciplinary will likely be critical to the solution of complex problems [6]. Today, engineers are no longer singularly required to have expertise in a specific technical skill area. Technologies are changing and the boundaries in and between disciplines are less defined. Future engineers will have to be able to transcend disciplinary limitations, work in different fields, and master communication and collaboration skills. To create competitive advantage, students should be enabled to establish innovative methods of knowledge collection and creation through digital transformation and collaboration across various disciplines.

In education, knowledge creation methodologies have not been fully applied to various learning settings. Few schools teach students to create knowledge, however, others still deal with knowledge as static and complete, and become experts at consuming knowledge rather than producing it [1]. This paper explores a transforming pedagogy that is based on reflective practice and redesign of learning tasks to provide teachers and learners with a platform of knowledge creation. This process requires teachers to play a key role by encouraging, identifying and fostering creativity, and institutions to make knowledge readily available and easily retrievable for an education that better fits the times. 


\section{KnOWLEdGe Creation AND InNovation}

Today's students do not learn just by sitting in classes listening to teachers, memorizing materials, and preparing answers. They think about what they are learning, write about it, reflect it to past experiences, and apply it to what they feel is important. They make what they learn a part of themselves [7].

According to the theory of knowledge creation, there are two dimensions of knowledge creation; epistemological and ontological, as shown in Fig. 1. The epistemological knowledge creation dimension consists of tacit and explicit knowledge while the ontological knowledge creation is concerned with the levels of knowledge and creating entities at the individual, group, and organizational levels [8]. Tacit and explicit knowledge are converted into organizational knowledge through the socialization, externalization, combination, internalization (SECI) model of knowledge creation [9] which is seen as a source of continuous innovation.

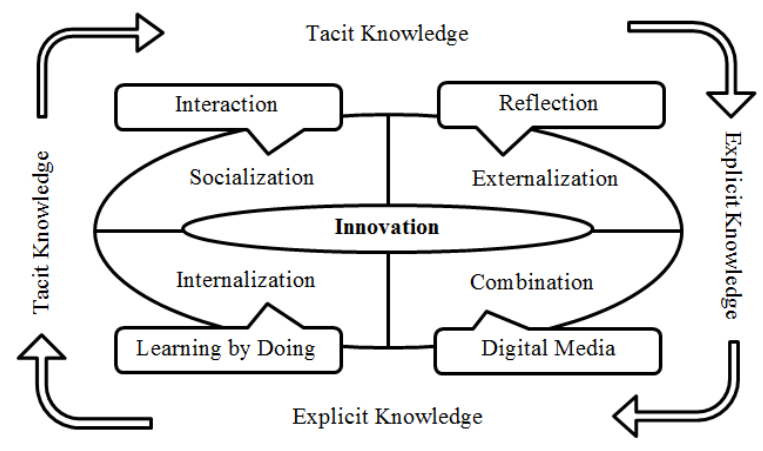

Fig. 1. Dimensions of knowledge creation and innovation.

Explicit knowledge describes knowledge that can be articulated through words, diagrams, formulae, computer programs, and similar means and can be readily transmitted to other people. It can either be represented in the form of mental representations in the human brain or in its physical form by means of language or writing [8].

Tacit knowledge refers to knowledge bound to an individual and to a particular context that is difficult to articulate and formalize through means like language or writing [9]. The "know-how, mental models, ways of approaching problems, and organizational routines" are a few categories of tacit knowledge which can be achieved only by internal individual processes like experience, reflection, internalization or individual talents. Thus, it cannot be managed and taught in the same mode as knowledge which is explicit. It is mostly stored only in human beings, while explicit kind of knowledge can be stored in a technological or mechanical way, like in information systems or handbooks [10].

Socialization (tacit to tacit) describes the sharing of tacit knowledge between individuals as typically occurring through joint activities in combination with physical proximity, for example during an apprenticeship [11]. It starts with building an environment of interaction that facilitates sharing of experiences. Knowledge is passed on through practice, guidance, imitation, and observation. In the classroom, this process could be utilized in generating ideas of projects or assignments.
Externalization (tacit to explicit) is the process of articulating tacit knowledge into explicit concepts. Since tacit knowledge can be virtually impossible to codify, the extent of this knowledge conversion mechanism is debatable. By applying meaningful reflection, tacit knowledge is translated into explicit concepts, which are comprehensible to a larger group.

Combination (explicit to explicit) describes the process of converting existing explicit knowledge into new and more complex sets of explicit knowledge by methods like editing, sorting, classifying, and structuring.

Internalization (explicit to tacit) is the process of embodying explicit knowledge into tacit knowledge. It is related to learning by doing (LBD) when experiences through socialization, externalization and combination are internalized into individuals' tacit knowledge [11].

\section{REFLECTING Digitally}

The current view on the typical educational basis of professional engineering practice may be summarized in the following acquisition parts: basic science knowledge, applied science knowledge, and specific skills to support practice [12]. The above view leads to a situation where practitioners are problem definers and solvers who select means best suited to particular purposes [13]. The required means is revealed only in the action of doing; it is thinking while doing. Schon [12] terms this activity "reflection-in-action" and advocates that students must learn "a kind of reflection-in-action that goes beyond statable rules". To achieve the above he suggests two modes of operation within a teaching environment: telling and listening, and demonstrating and imitating. The first mode is familiar to typical engineering education, while the second mode requires the tutor to demonstrate how to, for example, design something followed by imitation by the student. This requires the tutor and student to work together on solving an open-ended problem [14] that is new to both of them.

Learning institutions are built largely around the "teacher-content-student" set of interactions. Educators produce content to instruct students and students respond to select and probably create content to provide evidence of their learning. In this scenario, digital environment allows for significant enrichment at the interface levels. It empowers learners to become content producers instead of passive consumers. Unique to this environment, content can be changed dynamically in response to learner inputs to provide personalized instruction. Therefore, any pedagogical innovation must equip learners with the skills and competencies to function in a digital culture. This requires meaningful environment to exploit available resources to create learning experiences that are motivating and engaging, yet relevant and challenging.

As part of classroom task to develop educational reflective practice, a systematic process for deep learning and knowledge creation was established for an electrical engineering course, "Electric Power Transmission, Distribution and Utilization Systems," known by its course code ELG4125. To achieve the goal, case-based learning (CBL) and project-based learning (PBL) are usually implemented in the course and the instructor acts 
as a facilitator in the construction of knowledge. Both the case and related projects are based on authentic open-ended real-world problems with clear tips. It aims at teaching material on a "need to know" basis where students become researchers and gather knowledge, then decide from among the best solution. Both CBL and PBL employ the 4Cs principle: critical thinking, communication, collaboration and creativity, with outcomes tied to curriculum and learning goals.

The topic of "a smarter grid" was chosen as a teaching medium for the 10 -week case. This system as a whole makes the case worthy of reflection, technically and pedagogically. The case narrative is accompanied by supporting information and scaffolding tools that facilitate knowledge creation including research articles, simulation results, and video developing. Students are asked to develop an "ePortfolio" that includes the design details and summary of results. The ePortfolio reflects the student's progress in self-directed design with a summative "ePoster" type of concluding outcomes.

For the 8-week open-ended design projects, groups of two students convened on a weekly basis. The class projects were executed by 74 students convened into 37 groups where students come up with their own questions to solve and the instructor facilitates discussion in group level. These are collaborative CBL support projects which were largely based on the dual concepts of "green buildings" and "LEED certification". The projects focused on green homes, schools, apartments, campus buildings, arenas, airports, and hotels representing smart loads in the evolving grid. Final submission was in the form of a 3-minute video which reflects the engineering design aspects of the building. In addition, ten videos were presented during a University event created by the class "Greening Curriculum, Campus, and Community: http://www.greenengineers.ca/SEEDS.htm". However, all the 37 videos were presented during an evaluation session at the end of the semester.

In general, videos are digital artifacts that incorporate reflection on what students have done; deliberately analyze decision making, draw on knowledge content and connect it to what they do. Improvement comes by applying that reflection in the evaluation activity.

\section{EVALUATION AND QUESTIONNAIRE}

Evaluation that focuses on student mastery of core academic content and the development of deeper learning skills such as critical thinking, problem-solving, collaboration, and communication should be a high priority [1]. Self-awareness may be raised through selfand peer evaluation, which are known to assist students in developing professional skills such as reflection and empowerment. Evaluation refocuses thinking on existing knowledge and helps generate new knowledge and ideas.

The course ELG4125 is taught with a goal of knowledge creation in mind. At the end of the semester, a project video presentation session was organized. Students were asked to peer evaluate the 37 videos and take an end-of-class questionnaire. Every student in the class was invited to fill out a score sheet for each video presentation, rating them on a variety of criteria. Students did not have to add their names to the evaluation and questionnaire forms. Peer evaluation is one of the ways in which students internalize the characteristics of value work, using rubrics to evaluate performance and demonstrate reflection about learning. The evaluation provided an opportunity for students to assess the work of other team members. The process showed that students were willing to give honest feedback to peers and the course instructor as they gain experience with assessment. The entire process helps students reflect, become more self-aware, and adopt ownership over their learning.

When brainstorming for the questionnaire, the author thought of a single question about "knowledge creation and reflective practice in teaching and learning." The questionnaire starts with the following introduction: "Students do not learn by sitting in classes listening to teachers, memorizing materials, and preparing answers. They must think about what they are learning, write about it, reflect it to past experiences, and apply it to what they feel is important. They must make what they learn a part of themselves." The question was specific to the ELG4125 course major components: "The case-study e-Portfolio and project video reflect the above and made me more creative: disagree; rarely agree; agree; or strongly agree and recommend it for future classes." Results from the questionnaire showed that $60 \%$ of students "strongly agreed" with the learning approach and recommend course activities that reflect real life applications throughout digital portfolio and/or video creation for future classes. $31 \%$ of students "agreed" with the above methodology, while $7 \%$ only "disagreed" for various reasons including mainly the demanding creation process and the additional digital tools to acquire. This data shows that students want and expect more reflective learning approaches across the semester. Based on student comments, it is believed that teachers have an opportunity to proactively drive the motivation of their students to impact their' perspective on learning.

By engaging the entire class to digitally reflect on case study and support project tasks yielded deeper levels of learning. Because students were working on different tasks, they cannot all be anticipated to learn the exact same thing; however each student gained something different from this learning experience.

\section{LEARNING BY DOING}

Aristotle's wisdom that "the things we have to learn before we do them, we learn by doing them", as a principle for thousands of years, is often overlooked in the domain of typical education. Adjusting education to such ironic activity means embracing an open curriculum that provides learning from experiences resulting directly from one's own actions, as compared with learning from watching or listening. Pedagogically, LBD as a case for "experiential education" refers to several aspects of creating and applying knowledge.

Experiential education is when learners enthusiastically involve in activities or experiences. It is participative, either making or doing, which takes diverse forms. Students would learn through doing and reflect on those activities by applying knowledge to practical 
experience in order to develop skills or new ways of thinking [15]. Crucial success requirements of experiential education include space and resources, actual whole problem of no right answer, and a structure developed by the teacher who leads from alongside in new and creative ways. Cultivating the results of such education demands that learning environment should be transformed to support growth. Since reflection is such an important element of a successful experiential education, it is essential that students realize exactly what reflection is and how to utilize the process to develop their learning.

The learning-by-doing principle has been promoted widely and in many forms, including learn-by-doing, trial-and-error learning or discovery versus instruction, practical experience versus book learning, the practice-theory-practice dialectic, and proof upon practice [16]. Usually individuals apply the knowledge acquired through observations and direct reflections to real-life cases, which is known to be a factor that increases student motivation and empowerment [17].

There is a wide range of design models that aim to embed learning within real world contexts including laboratory, workshop or studio work. The focus here is on some of the approaches in which LBD can be designed and implemented, with respect to the use of technology, and to help develop the knowledge and skills needed in a digital environment.

In engineering, mechatronics is a discipline that reflects interdisciplinary real-life cases effectively. It is the synergic design of computer-controlled systems that integrates mechanical, electrical, and computer tools with information systems for the manufacture of products and processes. Such integration offers a wider spectrum of assignment potential and thereby also opportunities for student freedom in being creative [18]. The inclusion of mechatronics projects in engineering education benefits students, who are able to practice the design concepts that they have been taught while at the same time forming a strong foundation in principles. The projects are also rewarding, as they often afford the students their first opportunity to design and build their own systems [19].

Student mechatronic projects are a parallel part of the laboratory framework. The basic technical requirement for each project is the integration of electronics, software and mechanics to achieve a system or product. The author teaches the course ELG3336 (Electronics for Mechanical Engineering) to a third-year class. Students taking this course are encouraged to pick up a mechatronics project of their own interest that can be successfully completed in about 10 weeks. The project is a relatively open-ended learner-centric assignment where the students apply a typical iterative design process with no unique solution. These projects involve teams of three students and require the acquisition of components such as breadboards, sensors, motors, gears, controllers, and other accessories.

At the end of the semester, the class jointly exhibited 53 functioning prototypes where students shared the experience with each other as well as with visitors from local high schools and students from other classes. Exhibition of mechatronic projects represents a collaborative exercise that involves reflection on the subject matter from the viewpoints of different people and disciplines. Examples of student projects including videos are available at "g9toengineering.com."
Finally, it is unrealistic to expect students immediately to undertake a complex team-oriented design projects without familiarity with tools and skills supporting the design activity. Therefore, the course offers laboratory sessions to expose students to the required tools as well as to encourage teamwork and technical writing. By combining all above, the course ELG3336 is a recruitment hub for several student competition teams and entrepreneurial activities at the faculty Brunsfield Centre.

\section{KNOWLEDGE SHARING}

Knowledge sharing (storage and retrieval) and knowledge transfer are a precondition for engineering education to enable effective knowledge creation. It is the process where individuals jointly exchange their knowledge and mutually create new knowledge. Today, online knowledge sources allow for student access irrespective of temporal and geographical constraints, broadening access, however in many cases embracing the limits inherent in non-digital educational practices.

One of the approaches to overcome access limits and facilitate knowledge creation and sharing is the establishment of open educational resources (OERs). The OER definition coined by UNESCO [20] is an "open provision of educational resources, enabled by information and communication technologies, for consultation, use and adaptation by a community of users for noncommercial purposes." The primary motivation for the OER movement is the "powerful idea that the World's knowledge is a public good." The Web provides unprecedented opportunities to share that knowledge [21]. David Wiley [22] lists "5Rs" of openness that are helpful in this context: Retain - make, own and control; Reuse - use content for any purpose; Revise - adapt, adjust or modify; Remix - combine original or revised content with other open content to make new content; Redistribute the remixed work under similar license. Pedagogically, the trend towards openness benefits students by reframing their role from consumers to producers of knowledge [23].

To realize the above goal, two OERs, namely "g9toengineering.com" and "greenengineers.ca" were developed by the author in 2007 to support teaching a number of courses and to provide an open access to knowledge in various disciplines and topics. These OERs contain a set of activities and learner-generated content around the creation and use of engineering knowledge. The organization of the first OER is based on the SECI model of knowledge creation $[9,11]$ in the interdisciplinary field of mechatronics. This OER in particular, utilizes variations of the data-informationknowledge-wisdom (DIKW) hierarchy that cover a wide range of formats including general information, lecture notes, video clips, posters, diagrams and graphics.

The second OER is largely devoted to student project activities in the interdisciplinary area of green engineering. Both OERs are open access web-based knowledge sharing library populated with typical-based engineering curricula for use by K-12 teachers, engineering teachers and students, and the public to make science, technology, engineering, art, and math (STEAM) 
come alive through engineering design within an innovation environment. It may be applied to formal as well as informal education scenarios.

A key aspiration behind the articulation of these OERs is to provide learners with open access to a growing curricular resource of teaching and learning. The OERs involve combination of concepts, design, and practices that address engineering education in general. They integrate various dimensions of knowledge sharing including acquisition, possession, creation and competence that enhance innovation. In addition, the OERs are a key for public relations as a show-window for attracting new students. The author receives a lot of positive feedback from students, teachers and other users for the impact of the OERs.

\section{CONCLUSION}

Reflective learning facilitates learners to activate prior knowledge, and to develop their knowledge. To effectively realize this, certain adjustments in education system should take place where classes will be more open to diverse learning experiences and teachers will continue as mentors, guides, facilitators, designers and organizers of learning tools. This paper presents CBL, PBL and LBD within the framework of "acquire-reflect-share-apply" to facilitate knowledge creation and deep learning. Student feedback and data clearly show that unleashing engaging activities into web-enhanced/hybrid/blended paradigms where students receive traditional and technology-mediated learning may significantly improve student analytical thinking, reflective judgment, and self-efficacy. The emerging multimedia technologies and cloud capacity can promote learner autonomy and help articulate the key lessons taught by the experience. It also assists educators to facilitate reflection on learning practices by creating, enhancing, embedding, retrieving, and sharing knowledge more effectively.

\section{References}

[1] Charles Leadbeater and Annika Wong, Learning from the Extremes: A White Paper. San Jose, Calif., Cisco Systems Inc. Available as of April 20, 2018 from www. cisco.com/web/about/citizenship/socio-economic/docs/ Learning fromExtremes_WhitePaper.pdf.

[2] Richard M. Felder and Linda K. Silverman, "Learning and teaching styles in engineering education," Engineering Education, vol. 78, no. 7, pp. 674-681, 1988.

[3] Erik P. M. Vermeulen, Education Disrupted (Finally)! How New Technology is Transforming Teaching and Learning. Available as of April 20, 2018 from https://hackernoon.com/education-disrupted-finally-cec c1ba64506.

[4] Anna Sfard, "On two metaphors for learning and the dangers of choosing lust one," Educational Researcher, vol. 27, no. 2, pp. 4-13, 1988 .

[5] NAE, The Engineer of 2020: Visions of Engineering in the New Century, National Academy of Engineering. https://inside.mines.edu/UserFiles/File/Assessment/Eng r2020.pdf.
[6] Sami Paavola, Lassi Lipponen, and Kai Hakkarainen, "Models of innovative knowledge communities and three metaphors of learning," Review of Educational Research, vol. 74, no. 4, pp. 557-576, 2004.

[7] Salima Daud, Rabiah E. Abdul Rahim, and Rusina Alimun. "Knowledge creation and innovation in classroom," World Academy of Science, Engineering and Technology International Journal of Social, Behavioral, Educational, Economic, Business and Industrial Engineering, vol. 2, no. 4, pp. 440-444, 2008.

[8] Frank Neumann, An Integrated Descriptive Model of Knowledge Creation Applied to Mechatronic Product Development, PhD Thesis, Otto-von-Guericke-University, Lehrstuhl für Maschinenbauinformatik, 2014.

[9] Ikujiro Nonaka and Hirotaka Takeuchi, The Knowledge-Creating Company: How Japanese Companies Create the Dynamics of Innovation? New York, NY: Oxford University Press, 1995.

[10] Elizabeth A. Smith, "The role of tacit and explicit knowledge in the workplace," Journal of Knowledge Management, vol. 5, no. 4, pp. 311-321, 2001.

[11] Ikujiro Nonaka, "A dynamic theory of organizational knowledge creation," Organization Science, vol. 5, no. 1, pp. 14-37, 1994.

[12] Donald A. Schon, Educating the Reflective Practitioner: Toward a New Way of Teaching and Learning in the Profession, San Francisco: Jossey-Bass Publishers, 1987.

[13] W. P. A. Dias, and D. I. Blockley, "Reflective practice in engineering design," In: Proceedings of the Institution of Civil Engineers, 108, pp. 160-168, 1995.

[14] Leland M. Nicolai, "Viewpoint: An industry view of engineering design education," International Journal of Engineering Education, vol. 14, pp. 7-13, 1998.

[15] Linda H. Lewis and Carol J. Williams. In Lewis Jackson and Rosemary S. Caffarella, eds., Experiential Learning: A New Approach (pp. 5-16). San Francisco, CA: Jossey-Bass, 1994.

[16] Hayne W. Reese, "The learning-by-doing principle," Behavioral Development Bulletin, vol. 11, pp. 1-19.

[17] Ann Frymier, Gary Shulman and Marian Houser, "The development of a learner empowerment measure," Communication Education, vol. 45, no. 3, pp. 181-199, 1996.

[18] Riadh W. Y. Habash and C. Suurtamm, "Engaging high school and engineering students: A multifaceted outreach program based on a mechatronics platform," IEEE Transactions on Education, vol. 53, no. 1, pp. 136-143, 2010.

[19] Riadh W. Y. Habash, C. Suurtamm, and D. Necsulescu, "Mechatronics learning studio: From "play and learn" to industry-inspired green energy applications," IEEE Transactions on Education, vol. 45, no. 4, pp. 667-674, 2011.

[20] UNESCO, Forum on the Impact of Open Courseware for Higher Education in Developing Countries: Final report, UNESCO. Design, 2002 (July), pp. 1-3.

[21] Marshall S. Smith and Catherine M. Casserly, "The Promise of Open Educational Resources," Change: The Magazine of Higher Learning, vol. 38, no. 5, pp. 8-17, 2006.

[22] David Wiley, What is open pedagogy? Available as of January 25, 2017 from https://opencontent.org/blog/archives/2975.

[23] Rajiv Jhangiani, Ditching the "Disposable Assignment" in Favor of Open Pedagogy. Available as of April 20, 2018 from http://teachpsych.org/E-xcellence-in-Teaching-Blog/45 83103. 